\title{
NA BUSCA DA PERCEPÇÃO PERDIDA: CAMINHOS MERLEAU-PONTYANOS EM CLARICE LISPECTOR
}

Nilson Fernandes Dinis*

\section{A Fenomenologia da Linguagem em Merleau-Ponty}

$\mathrm{O}$

filósofo francês Maurice Merleau-Ponty inicia o prefácio de sua Fenomenologia da Percepção apontando as peculiaridades de seu método na busca do conhecimento:

\begin{abstract}
A Fenomenologia é o estudo das essências e todos os problemas, segundo ela, tornam a definir essências: a essência da percepção, a essência da consciência, por exemplo. Mas a Fenomenologia é também uma filosofia que substitui as essências na existência e não pensa que se possa compreender o homem e o mundo de outra forma senão a partir de sua facticidade (...) É a ambição de uma filosofia que pretende ser uma ciência exata, mas é também uma exposição do espaço, do tempo e do mundo vivido. (MerleauPonty, 1971, p. 5)
\end{abstract}

* Universidade Federal do Paraná. 
DINIS, N. F. Na busca da percepção perdida: caminhos...

Mas a busca das essências na fenomenologia de Merleau-Ponty não se realiza através de um distanciamento neutro, nem de um possível sobrevôo ao real, já que não há aqui possibilidade para um sensível puro. Ela se efetua no contato direto com o vivido, sendo que o ato perceptivo emerge de uma relação de encontro e imbricamento do sujeito e do objeto. A posição do sujeito que observa é sempre a partir de um ponto específico no mundo, o que torna nossas apreensões sempre parciais. E o que Merleau-Ponty combate em qualquer forma de conhecimento é justamente o "pensamento de sobrevôo", a crença de que a consciência humana pode colocar-se soberanamente como portadora da faculdade de julgar e explicar. Tal pensamento nos instalaria longe do "vivido". A particularidade do método de Merleau-Ponty está na busca da descrição da percepção. Portanto, não se trata nem de sua explicação, nem da sua análise, pois toda descrição da percepção implica em:

...retornar a este mundo antes do conhecimento do qual o conhecimento fala sempre, e com respeito ao qual toda determinação científica é abstrata (...) Este movimento é absolutamente distinto do retorno idealista à consciência e a exigência de uma descrição pura exclui tanto o procedimento da análise reflexiva quanto o da explicação científica. (p. 7)

Assim, Merleau-Ponty se coloca contra a disputa binarista entre posições idealistas e materialistas que sufocam e impedem a descrição do fenômeno. É antes mesmo das conceituações sobre as coisas, no plano pré-reflexivo, que se instala a descrição fenomenológica. Nem objetivista, nem subjetivista, pois tais posições são posteriores ao nosso contato perceptivo, pré-tético com o mundo. Estamos o tempo todo entrelaçados ao mundo e é deste prisma que a descrição e não a explicação dos fenômenos se torna possível. Mas vamos nos centrar na questão da linguagem para que possamos buscar adiante algumas articulações com a literatura. Contudo, para que possamos alcançar nosso objetivo, nos deteremos ainda mais um pouco em um conceito que é fundamental no projeto merleau-pontyano, o conceito de corpo vivido.

Como vimos, o plano do sensível em Merleau-Ponty será o plano de um imbricamento sujeito e objeto, ou melhor, corpo e mundo, de onde irão emergir os sentidos fundamentais de toda experiência. Mas a noção de "corpo" está longe de remeter a qualquer fisiologismo. Corpo não é mais um conjunto de 
órgãos, mas é do corpo vivido ou corpo sensivel que nos fala Merleau-Ponty, corpo que se localiza neste seu encontro com o mundo. $\mathrm{O}$ corpo vivido transcende o corpo fisiológico fazendo com que as relações e os limites entre o sujeito e objeto se tornem deslocáveis e ambíguas, tal como nos aponta o mais conhecido exemplo de Merleau-Ponty:

\begin{abstract}
Quando minha mão direita toca a esquerda, sinto-a como uma coisa física, mas no mesmo instante, se eu quiser, um acontecimento extraordinário se produz: eis que minha mão esquerda também se põe a sentir a mão direita. Nele (meu corpo) e por ele não há somente um relacionamento em sentido único daquele que sente com aquilo que ele sente: ocorre uma reviravolta na relação, a mão tocada torna-se tocante, obrigando-me a dizer que o tato está espalhado por todo o corpo, que o corpo é 'coisa sensitiva', sujeito e objeto. (Merleau-Ponty, 1989, p. 195)
\end{abstract}

Tal exemplo nos prepara para a ontologia do sensivel que advirá com $O$ Visível e o Invisível. A mão direita é sujeito? A esquerda é objeto? Ou ambas sujeito e objeto? Parece que tais questões deixam de ter importância quando nos preocupamos com a experiência sensível ou com a busca do ser bruto. A experiência tátil, o tocar e o ser tocado, bem como a experiência visível, ver e ser visto, emergem de um mesmo tipo de ser. $\mathrm{O}$ corpo pertence às duas ordens do sujeito e do objeto ao mesmo tempo. Tal relação pode ser transposta para a relação corpo e mundo. $\mathrm{O}$ corpo também pertence à ordem das coisas assim como as coisas também pertencem à ordem do corpo. É também no plano do sensível que estará a possibilidade de percepção do outro. O outro habita um mesmo campo sensível, embora não habite a mesma consciência. Mas a experiência sensível é uma espécie de entendimento anterior à qualquer clivagem sujeito-objeto ou consciência-mundo. Mundo e corpo são simultaneamente sujeito e objeto.

A ontologia do sensível em Merleau-Ponty, partindo do primado da percepção para descrever os fenômenos e, com esta, a reversibilidade das posições sujeito e objeto, permite o questionamento destas posições. O corpo é veículo do ser no mundo, assim, indagar sobre o corpo torna-se um indagar sobre a existência. No trato com a linguagem, Merleau-Ponty procura afastar também o binarismo pensamento e linguagem, tal como fez com o sujeito e o 
DINIS, N. F. Na busca da percepção perdida: caminhos...

objeto no ato da percepção. Rejeita, portanto, a idéia de signo enquanto indicativo, índice ou comentário da experiência real. Tal como o corpo exprime o espírito, a fala exprime o pensamento. Entretanto, na fala, Merleau-Ponty distingue duas dimensões:

...uma palavra falante e uma palavra falada. A primeira é aquela na qual a intenção significante se encontra em estado nascente. Aqui a existência se polariza num certo sentido que não pode ser definido por nenhum objeto natural, é além do ser que ela procura se reunir, e é porque ela cria a palavra como apoio empírico de seu próprio não ser. A palavra é o excesso de nossa existência no ser natural. Mas o ato de expressão constitui um mundo lingüístico e um mundo cultural, ela faz recair no ser o que tendia para além. Daí a fala falada que desfruta significações disponíveis como uma fortuna adquirida. A partir dessas aquisições de outros atos de expressão artística; os do escritor, do artista ou do filósofo tornamse possíveis. (Merleau-Ponty, 1971, p. 207)

O escritor visaria atingir a expressão primordial, na qual o exprimido não existe à parte da expressão, o signo não está ligado a significações pré-dadas e a exterioridade entre signo e significação é rompida. A fala, embora presa a um vasto número de sentidos adquiridos ou já constituídos, pode a cada momento inovar, criar novos sentidos, fazer uma linguagem nova. Se por um lado a linguagem antecede a fala, por outro, paradoxalmente, é recriada constantemente pela fala:

A linguagem é este aparelho singular que, como nosso corpo, nos dá mais do que nós ali colocamos, seja o que nós aprendemos em nosso pensamento ao falar, seja quando nós escutamos os outros. Pois quando eu escuto ou quando eu leio, as palavras não vêm sempre atingir em mim significados já presentes. Elas têm o poder extraordinário de me colocar fora de meus pensamentos, elas provocam fissuras no meu universo privado por onde outros pensamentos fazem irrupção (...) as palavras da linguagem que, consideradas uma a uma, não são mais que signos inertes aos 
quais correspondem apenas uma idéia vaga ou banal, se enchem de repente de um sentido que se transborda em outro quando o ato de falar os une em um mesmo todo. (Merleau-Ponty, 1960, p. 298)

No ato expressivo primordial: "Eu me exprimo quando utilizando todos os instrumentos já falados, eu os faço dizer algo que eles nunca tinham dito" (p. 113). Na experiência do sujeito que se expressa e fala, a fala está ligada ao pensamento, não existindo, portanto, qualquer pensamento sem linguagem. $\mathrm{O}$ pensamento não é representação e o sujeito que fala também não representa as palavras que utiliza. Não há relação exterior entre fala e pensamento, a fala é a própria presença do pensamento no mundo sensível.

A ciência, abordando a linguagem como pura emissão de sons, e a filosofia, encarando a linguagem como expressão imperfeita do pensamento, nunca alcançam a dimensão expressiva da linguagem porque analisam a linguagem separada do pensamento, sendo que para Merleau-Ponty é impossível pensar pensamento sem linguagem ou linguagem sem pensamento. O real quando abordado de forma reducionista torna impossível qualquer atividade descritiva e a percepção revela o mundo como transcendente aos nossos reducionismos. Porém, a pintura e a linguagem, utilizando como veículo a percepção, procuram nos colocar em contato com o ser bruto, pré-tético, anterior aos nossos reducionismos. Elas nos revelam um real além e aquém dos fatos e idéias. A pintura, neste ponto de vista, também já não é mais representação:

A visão do pintor não é mais um olhar sobre um exterior (...) o quadro, finalmente, não se refere ao que quer que seja entre as coisas empíricas senão sob a condição de ser primeiramente "autofigurativo", ele não é espetáculo de alguma coisa a não ser sendo "espetáculo de nada", rebentando a "pele das coisas" para mostrar como as coisas se fazem coisas e o mundo se faz mundo. (Merleau-Ponty, 1989, p. 66)

$\mathrm{Na}$ linguagem, as significações criam uma pluralidade de sentidos que sempre ultrapassam os significantes, onde, a partir de um código de expressão 
DINIS, N. F. Na busca da percepção perdida: caminhos...

já dado, o artista consegue engendrar sempre novas significações instituindo uma "expressão originária”:

O poder da linguagem (...) está no presente quando ela consegue ordenar as palavras-chave de forma a fazê-las dizer mais do que elas jamais disseram, quando ela se supera como produto do passado e nos dá assim a ilusão de ultrapassar toda palavra e ir às coisas mesmas, já que de fato nós ultrapassamos toda linguagem dada. (Merleau-Ponty, 1968, p. 58)

A ilusão de alcançarmos as coisas mesmas nos é dada nesta relação direta e originária com a linguagem que se expressa substancialmente na literatura. A linguagem mesma torna-se despercebida: “...seu triunfo é de se apagar e nos dar acesso, por detrás das palavras, ao pensamento mesmo do autor, de forma que acreditamos ter nos comunicado com autor sem palavras, de espírito para espírito" (p. 16-17).

\section{"O Ovo e a Galinha": percepção e linguagem em Clarice Lispector}

Procuremos agora os caminhos da literatura para tentarmos encontrar ressonâncias deste "ser bruto" ou o "pré-tético" merleau-pontyano. Essa nossa articulação entre o literário e o filosófico se dará na obra de uma escritora que prima justamente por uma transição intuitiva entre esses domínios: a escritora brasileira Clarice Lispector. Mais precisamente, nossa busca centrará atenção no conto "O Ovo e a Galinha", conto que faz parte do livro A Legião Estrangeira.

$\mathrm{O}$ conto analisado a seguir apresenta uma reflexão sobre a linguagem e sua tentativa de apreender os objetos através da percepção. Nele percebemos alguns dos temas persistentes na obra clariceana: a crise da linguagem, a crise existencial, a preferência pela trama ao enredo e a busca infindável do "indizível" da linguagem.

No conto citado, o narrador entra em contato com a percepção de um ovo. E o primeiro movimento que coloca o narrador-observador e a coisa 
observada em um mesmo plano é a visão. É interessante acompanhar no texto a alternância que se dá entre as palavras ver e olhar. O primeiro movimento do narrador é ver: "De manhã na cozinha sobre a mesa vejo o ovo" e só então "Olho o ovo com um só olhar” (p. 49). Para Merleau-Ponty, o olhar é justamente o aparelho que tem a capacidade de "concentrar a visibilidade esparsa e de acabar o que está esboçado no espetáculo" (1971, p. 315). O olhar, ao contrário do ver (ato fisiológico), permite ao narrador clariceano experimentar-se enquanto corpo perceptivo ou corpo vivido. Depois disso, o olhar "é o necessário instrumento que, depois de usado, jogarei fora. Ficarei com o ovo" (p. 49).

A intenção de se aprofundar nesta relação perceptiva leva o narrador a um deslocamento temporal, ao que Merleau-Ponty chamaria de um "tempo constituinte", lugar da transição entre os momentos temporais, uma espécie de multiplicidade de momentos que permite o deslocamento para um passado: "Ver um ovo nunca se mantém no presente, mal vejo um ovo e já se torna ter visto um ovo há três milênios", bem como para um futuro: "Ver um ovo é a promessa de um dia chegar a ver o ovo" (p. 49).

Desde o início, o narrador se coloca contra toda tentativa objetivizante: "O ovo não tem um si-mesmo" (p. 49). Seria errado pensarmos o texto como uma busca da essência, a busca do narrador visa instalar-se no mundo perceptivo no qual sujeito e objeto se misturam. A totalidade do objeto percebido nunca é totalmente expressa, por isso "o ovo é supervisível". Permite sempre instalarmos em um novo ângulo perceptivo, impossível nos desvencilharmos de um partis pris. O caminho da razão e dos pressupostos lógicos é recusado pelo narrador: "Tomo o maior cuidado de não entendê-lo. Sendo impossível entendê-lo, sei que se eu o entender é porque estou errando. Entender é a prova do erro. Entendê-lo não é o modo de vê-lo" (p. 50). Portanto, o entendimento da razão e o pensamento lógico, porque fazem parte do pensamento reducionista de sobrevôo, são incapazes de expressar esse mundo perceptivo.

No jogo da visibilidade, sujeito e objeto se perdem entre ver e ser visto: "O ovo me vê. O ovo me idealiza? O ovo me medita? Não, o ovo apenas me vê - É isento da compreensão que fere” (p. 50). E a expressão artística estará aqui sempre a frente do seu tempo: "O ovo vive foragido por estar sempre adiantado demais para a sua época - Ovo por enquanto será sempre revolucionário” (p. 51). É impossível uma visão eidética do objeto longe da via perceptiva: "Fora de cada ovo particular, fora de cada ovo que se come, o ovo não existe" (p. 53). O real, a essência, é a via perceptiva. Como acentuaria Merleau- Ponty: “....a própria fragilidade de tal percepção atestada pelo seu desaparecimento e pela substituição por outra percepção, longe de nos autorizar a apagar nelas todas o índice de 
DINIS, N. F. Na busca da percepção perdida: caminhos...

realidade, obriga-nos a atribuí-lo a todos, a reconhecê-las todas como variantes de um mesmo mundo..." (1971, p. 49)

Daí a proliferação de construções no texto que tentam definir a essência do ovo com a utilização do verbo ser: "o ovo é supervisível", "o ovo é óbvio", "o ovo é uma coisa suspensa", "ovo é uma exteriorização" etc... O ovo, no texto clariceano, parece ser o símbolo de uma substância original que daria origem a todos os processos de diferenciações, assim o narrador nos diz: "Quanto ao que veio antes foi o ovo que achou a galinha" (p. 52). Nesse domínio originário as cisões sujeito e objeto, pensamento e linguagem, conteúdo e forma, perdem qualquer sentido. Pensar pensamento sem linguagem, ou o conteúdo sem a forma, equivale a quebrarmos a casca do ovo: "Pego mais um ovo na cozinha, quebro-lhe a casca e a forma. E a partir deste instante nunca existiu um ovo" (p. $54)$.

A relação entre o ovo e a galinha nos diz também de nossa condição humana de distanciamento desta percepção originária do ser bruto. Para sobrevivermos, necessitamos nos adequar às visões habituais do mundo que nos cerca: "É necessário que a galinha não saiba que tem um ovo" (p. 52). Porém, a alienação da galinha provém do fato de acreditar ser uma vida interior: "Para falar a verdade a galinha só tem mesmo é vida interior" (p. 52). O aprisionamento no "eu" afeta a capacidade de percepção, impede o corpo de se diluir no contato pré-tético com o mundo, no resgate do ser bruto: "A que pensou que eu significa ter um si-mesmo. As galinhas prejudiciais ao ovo são aquelas que são um "eu" sem trégua. Nelas o "eu" é tão constante que elas já não podem mais pronunciar a palavra 'ovo"” (p. 53).

O contato com o mundo originário tem como preço a condição de marginalidade, de deslocamento dentro de uma sociedade com visões e definições tão cristalizadas o que obriga também o narrador à condição de "agente disfarçado ": "Faço parte da maçonaria dos que viram uma vez o ovo e o renegam como forma de protegê-lo" (p. 54). É fácil associarmos a posição de agente ao escritor, sempre deslocado no seu tempo, exatamente por romper com a visão cotidiana das coisas e que, no contato com seu "ovo", tenta expressar o mundo de forma originária.

Indícios biográficos também escapam do texto: "O falso emprego que me deram para disfarçar a minha verdadeira função, pois aproveito o falso emprego e dele faço o meu verdadeiro..." (p. 55). Clarice Lispector, esta "fenomenóloga do indizível", para sobreviver se submete a escrever crônicas para o jornal, ocupação esta que dizia claramente detestar. Assim, o conto "O Ovo e a galinha" apareceu primeiro como crônica no ano de 1969, e só depois foi publicado em livro. Clarice sabe que seu estilo não se enquadra na forma de crônica para um 
DINIS, N. F. Na busca da percepção perdida: caminhos...

jornal popular, mas aproveita do falso emprego para criar preciosidades literárias como o conto "O Ovo e a galinha". A condição de "agente disfarçada" irá seguir Clarice pela sua vida, em uma época em que os escritores de destaque são homens e em que a literatura no Brasil se volta para o regionalismo. Na sua literatura de caráter intimista Clarice viverá sempre a condição de estrangeira.

\section{Na busca do ser bruto: ressonâncias entre literatura e filosofia}

A obra literária provoca ressonâncias com a análise fenomenológica porque se caracteriza pelo perspectivismo, cuja fonte é o seu traço de incompletude ou potencialidade, no qual o narrador está sempre se deslocando. "Há uma coisa que me escapa o tempo todo" (Lispector, 1993, p. 78). A literatura clariceana também pode ser vista como conseqüência dos movimentos modernistas de vanguarda iniciados na Europa. A escritura de Clarice procura romper com o enredo fatual (como no conto analisado "O Ovo e a galinha"), embora muitos de seus textos não sejam totalmente desprovidos dele. Suas estórias abundam em simbologia e metáforas insólitas, compostas de originalidade e hermetismo. Clarice Lispector, na linha dos escritores intimistas, fará também da técnica do fluxo de consciência seu estilo. Este é, por exemplo, o estilo que predominará em Água Viva: "Escrevo ao correr das palavras" (1993, p. 40).

As personagens clariceanas estão mergulhadas no mundo cotidiano e, a partir da percepção, são levadas a uma realidade outra, que muito se aproxima da experiência sensível descrita por Merleau-Ponty. Tal momento é conceituado por alguns críticos como sendo um "momento epifânico" da personagem. A revelação do mundo sensível só se dá porque o momento da perpepção permite a troca de posições e o intercâmbio entre observador e coisa observada. É o que ocorre com as imagens de animais tão presentes na maioria de seus textos: “Às vezes eletrizome ao ver bicho. Estou agora ouvindo o grito ancestral dentro de mim: parece que não sei quem é mais a criatura, se eu ou o bicho" (1993, p. 54).

Embora envolvidas na ânsia de conhecer e penetrar os mistérios, as personagens clariceanas têm paradoxalmente como obstáculo o medo e a angústia do desconhecido. Como exemplo, temos a personagem Ana do conto "Amor" em Laços de Família. Ana é uma simples dona-de-casa que, no contato com um cego mascando chicletes, se vê transportada para um mundo desconhecido: "Ela apaziguara tão bem a vida, cuidara tanto para que esta não explodisse" 
DINIS, N. F. Na busca da percepção perdida: caminhos...

(1982, p. 22). Assim há nos textos clariceanos uma dupla libertação: o da personagem, que consegue atingir a experiência sensível no momento epifânico, e o da autora, que consegue liberar a palavra através de sua obra artística. Em algumas situações, a personagem clariceana não consegue atingir a libertação. Ana, por exemplo, depois de seu contato com o cego, este ser que vive mais diretamente da percepção como um todo, um não-escravo da hegemonia normatizante da visão, prefere voltar ao mundo já cristalizado e apaziguado de seu cotidiano familiar, afastando-se do perigo de viver.

No seu trabalho literário, o escritor também procura aproximar-se da expressão originária: "quero me alimentar diretamente do plasma"(1993, p. 13). Nessa busca, o aparelho perceptivo, ou o ser no contato direto com o mundo, tem predileção como meio para o conhecimento: "Ouve-me então com o teu corpo inteiro" (p. 14). Nas críticas do narrador ao pensamento lógico poderíamos ler as mesmas críticas de Merleau-Ponty ao pensamento de sobrevôo: "Que mal porém tem eu me afastar da lógica? Estou lidando com a matéria-prima. Estou atrás do que fica atrás do pensamento" (p. 17).

Porém, a passagem para a vivência sensível só se dá na obra de Clarice Lispector através e graças à angústia. O momento epifânico implica numa ruptura com os modos tradicionais de visão-descrição de um fenômeno, o que leva a personagem a um momento de crise: "Como te dizer? É terrível e me ameaça. Sinto que não posso mais parar e me assusto" (p. 23).

A sensação de estranhamento nos personagens clariceanos não é provocada por uma metamorfose da coisa, uma vez que esta permanece a mesma, mas por um desvelamento de seus atributos inusitados. E para isso, é preciso lançar fora o que repetidamente foi dito sobre elas, abandonando todos os pressupostos e preconceitos com relação a elas. A essência, porém, não existe além do objeto, uma vez que não se pode fazê-la surgir "inteiramente nua" por estar "sempre vestida", agregada ao sensível (Merleau-Ponty, 1971, p. 112). Em outros termos, é no visível que se recupera o invisível.

Porém, a busca filosófica, ao contrário da literária, “...não se interessa pelas significações das palavras, não procura substituto verbal para o mundo em que vivemos, não o transforma em coisa dita, não se instala na ordem do dito ou do escrito" (p. 18). Assim, Clarice Lispector, sendo escritora, interessa-se pelo mundo concreto das palavras, já que elas são a matéria que possibilita a recriação das coisas. E mesmo a linguagem em Merleau-Ponty “...não é uma máscara sobre o ser, mas, se soubermos apreendê-la com todas as suas raízes e com toda a sua floração, é o mais válido testemunho do Ser" (p. 123). Se Clarice acentua o aspecto concreto da palavra é porque acredita que o significante é o corpo, a matéria onde o ser se inscreve e se diz: "E se tenho aqui que usar-te 
palavras, elas têm que fazer um sentido quase que só corpóreo, estou em luta com a vibração última" (Lispector, 1993, p. 81) .

A proposta de liberação das palavras consiste não somente em deformar, mas em revelar o incomum, o não visto, em produzir a sensação de estranhamento que toma conta dos personagens clariceanos. Na ânsia de tornar visível a essência que se cola ao próprio visível, mas que não é percebida em razão dos rótulos, das idéias pré-concebidas com as quais etiquetamos as coisas, é que o escritor se volta para a vivência imediata com o mundo:

...na pintura como na escritura procuro ver estritamente no momento em que vejo - e não ver através da memória de ter visto num instante passado. O instante é este. O instante é de uma iminência que me tira o fôlego. O instante é em si mesmo iminente. Ao mesmo tempo que eu o vivo, lanço-me na sua passagem para outro instante. (Lispector, 1993, p. 81)

Ocorre então uma relação de interpenetrabilidade mútua entre a percepção, o corpo, a vida do escritor e a construção de sua obra artística, o que também está expresso na filosofia de Merleau-Ponty através da idéia de "sistema de equivalência”. A linguagem, nossa forma de expressão, está de tal forma imbricada com o "corpo vivido" que torna impossível qualquer discurso neutro e objetivo, longe de nossa vivência perceptiva. Na obra do artista, arte e vida se misturam tornando impossível sairmos da linguagem. Isso a tal ponto que, na leitura de Merleau-Ponty, mesmo Paul Valéry, ao tentar fazer uma crítica da linguagem, acaba por realizar uma "obra sobre a negação de toda obra" (1960, p. 25).

Mesmo desconfiando da linguagem, a única forma para nos expressarmos acerca dela é instalando-nos na mesma e exercendo-a: "A crítica da linguagem e da vida, justamente se ela é radical, ela envolve inteiramente uma prática da linguagem e da vida" (p. 27). A linguagem torna-se então um instrumento que fazemos voltar sobre si mesma, mas ainda assim estaremos presos apenas à sua função metalinguística. E, além disso, o que é mágico na linguagem é que ela é plurisignificativa, sempre podemos nos instalar nela e criar um novo sentido, reinstituirmos sua função originária. 
DINIS, N. F. Na busca da percepção perdida: caminhos...

No encontro com a escritura clariceana, pudemos observar também sua insistência em uma forma de conhecimento que visa a apreender com o "corpo todo". Vida e escritura em Clarice Lispector estão de tal forma imbricadas que para a escritora viver é escrever e escrever é viver: "Escrever é procurar entender, é procurar reproduzir o irreproduzível, é sentir até o último fim o sentimento que permanecia apenas vago e sufocador". A busca da expressão em Clarice só se dá através de uma intensificação da experiência perceptiva, daí o entrelaçamento entre vida e obra. Atrás de suas personagens, o autor é apenas mais uma, o que lhe permite dizer: "Escolher a própria máscara é o primeiro gesto voluntário humano".

Sua opinião acerca de cisões como conteúdo e forma é clara: "Para falar a verdade, não se pode pensar num conteúdo sem forma. Só a intuição toca na verdade sem precisar nem de conteúdo nem de forma" (Lispector, 1992, p. 271).

Clarice, enfim, é aquela que busca dizer o "indizível”, que tenta "captar a quarta dimensão do instante já que de tão fugidio não é mais porque agora tornou-se um novo instante que também não é mais" (1993, p. 13). Esse incessante deslocamento, longe de tal fato impossibilitar a criação literária, é o que sempre instigará o escritor a criar mais nos apresentando sempre o mundo de uma forma inusitada, como se fosse nosso primeiro olhar sobre o mesmo: "E no entanto cada vez que vou escrever é como se fosse a primeira vez. Cada livro meu é uma estréia penosa e feliz. Essa capacidade de me renovar toda à medida que o tempo passa é o que eu chamo de viver e escrever" (1992, p. 99).

\section{RESUMO}

O objetivo deste artigo é realizar uma incursão pelo trajeto merleau-pontyano, principalmente pelos textos que interceptam a questão da linguagem, e indicar pontos de tangência no projeto merleau-pontyano de atingir o ser bruto e a experiência literária presente nos textos de Clarice Lispector.

Palavras-chave: Clarice Lispector, Maurice Merleau-Ponty, fenomenologia, literatura brasileira. 


\begin{abstract}
This article aims an incursion upon Merleau-Ponty's philosophy, mainly the texts about the question of the language. Then we will try to point to some similarities in Merleau-Ponty's project of reaching the brute being and the literary experience of Clarice Lispector.

Key-words: Clarice Lispector, Maurice Merleau-Ponty, phenomenology, brazilian literature.
\end{abstract}

\title{
REFERÊNCIAS
}

LISPECTOR, C. Água viva. Rio de Janeiro: F. Alves, 1993.

. A descoberta do mundo. Rio de Janeiro: F. Alves, 1992.

. Laços de família. Rio de Janeiro: J. Olympio, 1982.

. A Legião Estrangeira. São Paulo: Ática, 1977.

MERLEAU-PONTY, M. Textos selecionados. São Paulo: Nova Cultural, 1989.

_. Fenomenologia da percepção. São Paulo: F. Bastos, 1971.

_. La Prose du Monde. Paris: Gallimard, 1960.

_. Resumés du Cours. Paris: Gallimard, 1968.

_. Signes. Paris: Gallimard, 1960.

. O visivel e o invisível. São Paulo: Perspectiva, 1971.

NUNES, B. O drama da linguagem: uma leitura de Clarice Lispector. São Paulo: Ática, 1995.

SÁ, O. de. A escritura de Clarice Lispector. Petrópolis: Vozes, 1979. 